REVISTA DE DERECHO UNED, NÚM. 18, 2016

\title{
UNA REFLEXIÓN SOBRE EL DERECHO A LA ASISTENCIA SANITARIA COMO DERECHO SOCIAL Y UNIVERSAL CON FINANCIACIÓN PÚBLICA ${ }^{1}$
}

\author{
A REFLECTION ON THE RIGHT TO HEALTH CARE AS SOCIAL \\ AND UNIVERSAL RIGHT WITH PUBLIC FUNDING
}

\author{
Jesús Esteban Cárcar Benito \\ Doctor en Derecho por la UNED y Facultativo No Sanitario \\ del Servicio Murciano de Salud
}

Resumen: El derecho social a la atención sanitaria precisa, además, para ser plenamente efectivo, una nueva ordenación de las relaciones del Sistema Nacional de Salud, que incluya una perspectiva de los derechos fundamentales. La Ley General de Sanidad, sin embargo, no estableció de forma clara los principios ni los criterios necesarios para conformar el sistema sanitario que planteaba, ni para conseguir de manera efectiva los objetivos generales de universalidad y protección pública. La extensión de la cobertura sanitaria en España y la percepción de garantía y seguridad por parte de los ciudadanos en relación con los servicios sanitarios, factor importante de cohesión social, es uno de los grandes logros, pero resulta inacabada como derecho social. Al mismo tiempo, la compleja interrelación que se ha permitido en la actual coyuntura económica ha imposibilitado la evolución del concepto de aseguramiento universal, que sigue siendo un reto para el sistema de protección social en España, que está definida en los derechos sociales y son el objeto de este estudio.

Abstract: The social right to health care needs also to be fully effective, a new management relation National Health System, includ-

${ }^{1}$ Artículo dentro del Proyecto Der 2013-41462-R. 
ing a perspective of fundamental rights. The General Health Law, however, is not clearly established the principles and criteria necessary to shape the health system posed, or to achieve effectively the general objectives of universality and public protection. The extension of health coverage in Spain and the perception of security and safety of citizens in relation to health services, an important factor of social cohesion, is one of the great achievements, but it is incomplete as a social right. At the same time, the complex interrelationship that has been allowed in the current economic situation has hindered the development of the concept of universal insurance, which remains a challenge for the social protection system in Spain, which was defined in social rights and are the object of this study.

Palabras clave: asistencia sanitaria, derecho social, universalización.

Keywords: health care, social right, universal.

Recepción original: 27/02/2016

Aceptación original: 6/04/2016

Sumario: I. Introducción. II. El derecho a la asistencia sanitaria: un derecho social. III. La responsabilidad y el sujeto obligado en el derecho a la asistencia sanitaria: su perímetro. III.A La concreción de lo responsable. III.B El perímetro de la responsabilidad: necesidades, bienes y reversibilidad. IV. La subjetivización del derecho a la asistencia sanitaria. IV.A La protección de la salud y su parte programática. IV.B Efectividad, expectativa y derecho público subjetivo. V. La universalización del derecho subjetivo a la asistencia sanitaria: el largo proceso del marco normativo y sus propuestas. VI. Conclusión para una universalización del derecho social a la asistencia sanitaria.

\section{INTRODUCCIÓN}

El derecho a la asistencia sanitaria constituye un verdadero derecho, con algunas restricciones, que tienen que ver con la extensión de la prestación reclamada, como indica LORA, si bien su amplitud no nos lleva a un concepto de salud, en un genérico aseguramiento de la felicidad individual. Por otra parte, el hecho de que la obligación de protección de la salud no pueda declinar universalmente sobre los individuos en general, puesto, que estamos «ante el despliegue de accio- 
UNA REFLEXIÓN SOBRE EL DERECHO A LA ASISTENCIA SANITARIA...

nes que exigen una pericia y conocimiento técnico especial $»^{2}$. Su contenido, aunque parcial desde la óptica del art. $43 \mathrm{CE}$, es seguramente el más relevante para los ciudadanos en su conjunto o, al menos, se refiere a los aspectos de la protección de la salud a que la conciencia social es más sensible, y respecto de los que la demanda ha sufrido un incremento espectacular en los últimos años, cuantitativa y cualitativamente. Este derecho diverge del más genérico de la protección de la salud, confirmando que la distinción entre ambos no es un ejercicio intelectual estéril, sino que tiene pleno sentido, al menos en el ámbito jurídico ${ }^{3}$. El contenido del derecho es, por lo tanto, el de la recepción de una prestación consistente en el mantenimiento y recuperación de la salud. Es decir, un derecho a que el Estado disponga un mecanismo que garantice dichos servicios preventivos y curativos.

Actualmente el carácter de bien público de asistencia sanitaria y su relación con la supervivencia de las sociedades otorga a la legislación de salud uno de sus rasgos más importantes: la necesidad de conferir prioridad al bienestar general sobre cualquier otro interés. Con tal fin deben crearse los medios para colocarla al alcance de todos, no solo en condiciones de igualdad, sino también en el marco de la justicia distributiva sustentada en la necesidad de impartir diferente tratamiento de acuerdo con cada situación. Su reconocimiento forma el medio más importante por conducto del cual el derecho cumple sus fines o, mejor aún, se orienta al logro del bien común. En el caso de la legislación de salud, en particular, el bien común se relaciona con la salvaguarda o preservación del ser humano en toda su magnitud y, como consecuencia, de la sociedad como un todo ${ }^{4}$. El bien jurídico a proteger, como bien garantizado por el derecho, es la salud.

Empero, en una primera fase de las muchas dificultades que se conjugan contra su existencia, el aseguramiento social de la enfermedad es hoy una realidad generalizada, se debe ello a dos objetivos ele-

${ }^{2}$ LORA P.; ZUÑIGA FAJURI A., El derecho a la asistencia sanitaria. Un análisis desde las teorías de justicias distributivas, Iustel, Biblioteca Jurídica Básica, pp 197-198.

${ }^{3}$ En el Acuerdo de la Subcomisión Parlamentaria para la Consolidación y Modernización del Sistema Nacional de Salud, adoptado el 30 de septiembre de 1997, ya se preveía la instrumentación de la reforma legal adecuada que permita, entre otros objetivos, los siguientes: a) Fijar los contenidos y el carácter del derecho a la asistencia sanitaria como derecho público subjetivo, personal y no contributivo, y garantizar tanto la igualdad del contenido del derecho de cada uno de los ciudadanos, sin que existan discriminaciones por razones personales, profesionales o territoriales, como el acceso equitativo a sus contenidos materiales. b) Llevar a cabo la universalización efectiva del derecho a la asistencia sanitaria, extendiéndolo a todos los grupos sociales y desvinculándolo de los regímenes de afiliación de la Seguridad Social.

${ }^{4}$ ALONSO OLEA, M., Instituciones de Seguridad social, Capítulo octavo, Civitas, 1982, pp. 171-1999. 
mentales. El primero es que real y verdaderamente, la enfermedad, en cuanto tiene una cierta intensidad, está fuera de las medidas ordinarias de previsión del individuo aislado; y que tiende a estarlo más a medida que crece el costo de la asistencia sanitaria exponencialmente. El segundo que la asistencia sanitaria dada a la generalidad de la población se descubrió insuficiente; la prestada a los sectores no privilegiados económicamente de la población no estaba en concordancia con el nivel medio asistencial alcanzado. En este ámbito, la protección por la seguridad social ha sido en muchas ocasiones un medida de política social, a través de la cual se mejora el estado sanitario de la población y se hace a toda ella participe de los avances sanitarios contemporáneos, que son elemento esencial del nivel de vida de la población y pilar de cualquier política de bienestar social.

La enfermedad se caracteriza también por tener dos consecuencias, a exponer: un exceso de gastos sobre los habituales y corrientes, y todos los que son precisos invertir en la asistencia sanitaria tendente a la recuperación de la salud del enfermo. Un defecto de ingresos en cuanto que la enfermedad de cierta gravedad incapacita para el trabajo e impide la obtención de rentas derivadas del mismo. Las medidas de seguridad social que se habilitan para la cobertura del riego deben intentar la protección contra ambos tipos de consecuencias; los problemas básicos del aseguramiento social de la enfermedad se centran sin embargo sobre la asistencia sanitaria ${ }^{5}$. En cualquier caso, en el momento actual, y una aseveración perfectamente asumible es que el aseguramiento de la enfermedad es en todos los países, con ciertos grados de desarrollo, la clave de todo programa de seguridad social, aunque es asumible que en los diversos países existan diferencias notables en cuanto la extensión de la cobertura, organización de los servicios, prestaciones previstas y participación del enfermo (asegurado) en los costes.

En consecuencia, es dable decir que para la seguridad social, la asistencia sanitaria es un conjunto de prestaciones que cubren determinados riesgos. Un análisis cierto, pues ya con la coherencia del derecho positivo, de los riesgos y las prestaciones, suscribe que tienen por fin conservar o restablecer la salud y la aptitud para el trabajo. La enfermedad es un tipo de riesgo que aceptablemente no dejará de existir afectando a individuos determinados, al propio tiempo es un

${ }^{5}$ MCKEOWN, TH, LOWE, C Introducción a la medicina social, México: SXXI editores. ( Cap: 2: Servicios médicos públicos, 1984, pp. 1848-1948;. Vid. MORENO, L., \& MARÍ-KLOSE, P. «Las Transformaciones del Estado de bienestar Mediterráneo: Trayectorias y retos de un régimen en Transición», en E. del Pino and M. Josefa rubio (eds), Los Estados de bienestar en la Encrucijada, Madrid: Tecnos, 2013, pp. 126-46. 
evento cuya actualización en siniestro es económicamente evaluable. Reúne así, la enfermedad las dos tipologías precisas para poder ser objeto de norma de la seguridad social. Se trata, además, de un riesgo genérico en el sentido de que la noción de trabajo por cuenta ajena no es imprescindible.

Ahora bien, en el Pacto Internacional de Derechos Económicos, Sociales y Culturales de 19 de diciembre de 1966, ratificado por España el 13 de abril de 1977 (BOE de 30 de abril), se manifiesta claramente lo que puede denominarse concepción amplia o «integral» del derecho a la protección de la salud, entre cuyos contenidos figura el derecho a la asistencia sanitaria o médica en caso de enfermedad. Con el uso del adjetivo "sociales», adicionado al término derecho se podría sostener que se hace referencia al sujeto titular del derecho, esto es, a la condición de los individuos que carecen de medios económicos insertos en una comunidad, en nuestro caso, para satisfacerse la asistencia sanitaria. Pero también podría decirse que se alude al destinatario del correspondiente deber como es el caso de la asistencia sanitaria, es decir, a la sociedad en su conjunto. Por último, se podría afirmar que la calificación alude al contenido de tales derechos en sentido estricto, o sea, a las exigencias socioeconómicas que se pretenden satisfacer como es la salud. Sin embargo, la vinculación del legislador por el reconocimiento constitucional de los derechos sociales también se ha hecho más evidente en la medida en que, primero la doctrina y luego los tribunales, confieren a estos los principios de una estructura compleja. Reconocen derechos subjetivos, protegen instituciones, y proclaman valores que los legisladores tienen que respetar y procurar realizar. Ésta última vertiente objetiva de los derechos condiciona al legislador. Por ello, este trabajo intenta indagar dentro de tres elementos (el sujeto titular del derecho, el sujeto obligado y el objeto del contenido), parte de una noción concreta de derecho subjetivo entendido como un correlato de una obligación (claim-right).

\section{EL DERECHO A LA ASISTENCIA SANITARIA: UN DERECHO SOCIAL}

La caracterización antes aludida nos lleva a señalar su naturaleza. Es decir, los derechos sociales en general, y el de asistencia sanitaria en particular, llevaría instalado un deber genérico consistente en que se bosqueje un esquema institucional de provisión de bienes y servicios básicos, sistema al que todos los individuos habrían de contribuir de acuerdo con su capacidad económica y sin que dicha contribución suponga anular el tipo de vida que uno ha decidido vivir. Sin embargo, 


\section{Jesús Esteban CÁrcar Benito}

la determinación del contenido del derecho a la salud presenta un desafío peculiar por su propia composición y amplitud de alcance (prácticamente todo tiene que ver con la salud física y mental) y por los avances médicos y técnicos en este campo. De esta manera supuesta podría señalarse, por ejemplo, que el alcance de la tutela en el primer nivel del derecho a la salud, precondición material de la democracia, siguiendo a WALDRON, comprendería obligaciones positivas de proveer a la educación sobre los principales problemas de salud y como un primer nivel de atención. Este primer nivel de atención se ligaría a las acciones más básicas o elementales del sistema de salud de manera de satisfacer las necesidades más frecuentes de la población. El segundo nivel del derecho a la salud podría abarcar exigencias sociales como, por ejemplo, el acceso a tratamientos experimentales, acceso a operaciones de cirugía plástica, provisión de medicamentos mínimamente mejorados cuyo beneficio marginal es nimio, o cobertura de tratamiento de reproducción asistida ${ }^{6}$.

Otra cuestión sería sí, esta extensión del derecho a la salud, el derecho a la asistencia sanitaria, como derecho social, está condicionado a los recursos con que cuenten los Estados para su implementación, mientras que los derechos civiles no oponen esta dificultad (no representan grandes costos la garantía de estos derechos). Los derechos económicos, sociales y culturales se encuentran condicionados a los recursos económicos que cuente el Estado para lograr su implementación. Cuando esos recursos abundan no hay riesgos para su cumplimiento; en cambio, la escasez de recursos imposibilita materialmente el goce de los derechos sociales. Esta crítica a los derechos sociales tienen dos aspectos relevantes: por un lado, resalta la estrecha relación entre recursos económicos del Estado y goce de los derechos sociales; y, por otro lado, los costos que suponen la implementación de los derechos sociales ${ }^{7}$.

Hay que exponer claramente lo condicional de los recursos para los derechos sociales: «reconocen y proclaman derechos cuya efectividad está subordinada al que hacer económico, hacen que venga a nuestra consideración, no la raigambre jurídica del derecho reconocido, la cual para nosotros está fuera de duda, sino la efectividad real del mismo y la positivización de aquellos que para algunos podría

${ }^{6}$ MORALES L., Derechos sociales constitucionales y democracia, Marcial Pons, 2015, pp. 322-ss.

${ }^{7}$ POGGE, T. W. World Poverty and Human Rights, Cosmopolitan Responsabilities and Reforms, Polity Press, Cambridge, 2002, p. 66. 
haber sido una simple abstracción conceptual más propia de la escolástica que de los momentos presentes» ${ }^{8}$.

De esta forma, resulta innegable la dependencia de los derechos sociales de los recursos económicos con los que cuente el Estado. Sin embargo, es apresurado establecer como argumento para el incumplimiento de los derechos sociales la ausencia de recursos económicos. Para ello, destaco una serie de argumentos. Cabe preguntarse si el Estado puede ser exonerado del cumplimiento de sus obligaciones ya sea de acción o de abstención- en la satisfacción de los derechos económicos, sociales y culturales a causa de la existencia de recursos limitados. Una lectura repentina del artículo 2.1 del Pacto Internacional de Derechos Económicos, Sociales y Culturales (PIDESC) podría sugerir que la satisfacción de estos derechos está condicionada a la disponibilidad de recursos. Sin embargo, el mismo Comité de Derechos Económicos, Sociales y Culturales de la ONU ha sostenido que "para que cada Estado Parte pueda atribuir su falta de cumplimiento de las obligaciones mínimas por falta de recursos disponibles, debe demostrar que ha realizado todo esfuerzo para satisfacer, con carácter prioritario, estas obligaciones mínimas». Además, no basta con que los estados demuestren la existencia de recursos limitados; tienen que evidenciar un uso eficaz, equitativo y oportuno de esos recursos. Por otra parte, aún en aquellos casos en los que el Estado demuestre una inequívoca limitación de recursos, ello no agota las posibilidades de satisfacción de los de derechos económicos, sociales y culturales, ya que éstos pueden ser cubiertos mediante programas desarrollados a través de la cooperación y la asistencia internacional. «Las obligaciones de satisfacción de los derechos económicos, sociales y culturales corresponden, por tanto, a los Estados, considerados estos individualmente, y en el conjunto integrado por la comunidad de las naciones. En este segundo grupo, deben incluirse los organismos multilaterales de los sistemas internacional y regional» ${ }^{9}$.

En cuanto al tema de los costos de los derechos sociales que imposibilitan su implementación como la asistencia sanitaria, acentúo la debilidad de esa argumentación porque «el recorte jurídico-estructural de un derecho no puede ni debe confundirse con la cuestión de su

\footnotetext{
${ }^{8}$ RAGA, T., «Efectividad de los derechos económicos y sociales», en Derechos y Libertades, Madrid, Universidad Carlos III-Boletín Oficial del Estado, Año III, n. ${ }^{\circ}$ 6, febrero 1998, p. 194.

${ }^{9}$ BOLIVAR, L., «La justiciabilidad de los derechos económicos, sociales y culturales: el papel de la sociedad civil», en Memoria I Curso Interamericano de Sociedad Civil y Derechos Humanos, San José (Costa Rica), Instituto Interamericano de Derechos Humanos, 1999, pp. 57-58.
} 


\section{Jesús Esteban CÁrcar Benito}

financiación. Si estas dos dimensiones fuesen indisociables, entonces no se comprendería que ciertos derechos -como los derechos de acceso a los tribunales y de acceso al derecho- pudiesen ser considerados tranquilamente derechos directamente aplicables cuando, sin embrago, dependen de prestaciones estatales (tribunales, procesos, etc.). (...). La reserva de las arcas del Estado supone problemas de financiación pero no implica el «grado cero» de vinculación jurídica de los preceptos que consagran los derechos fundamentales sociales» ${ }^{10}$. En esa misma línea argumental, la respuesta de los derechos sociales no depende de la disponibilidad de recursos, sino más bien en la asignación de los recursos disponibles ${ }^{11}$.

A la postre hay pasos relevantes en el plano internacional para que se adopte el Protocolo Adicional al PIDESC ${ }^{12}$ que establece un procedimiento de escrutinio por el Comité de Derechos Económicos, Sociales y Culturales, otorgándole competencia para comunicaciones o reclamaciones presentadas por los Estados y los particulares sobre violaciones a los derechos sociales. Se ha admitido progresivamente que el PIDESC no sólo obliga a los Estados a dar realización progresiva de los derechos económicos, sociales y culturales dentro de los límites derivados de los recursos disponibles, sino que impone obligaciones de efecto inmediato. En una reclamación individual se podría verificar si un Estado cumple o no esas obligaciones, las cuales serían «justiciables» ${ }^{13}$.

${ }^{10}$ GOMES CANOTILHO, J. J., «Metodología Fuzzy y Camaleones normativos em la problemática actual de lós derechos económicos, sociales y culturales» en Derechos y Libertades, Madrid, Universidad Carlos III-Boletín Oficial Del Estado, Año III, 1998, febrero, n. ${ }^{\circ} 6$, p. 45.

${ }^{11}$ CARAZO, R. A., "Los derechos económicos, sociales y culturales», en Memoria I Curso Interamericano de Sociedad Civil y Derechos Humanos, San José (Costa Rica), Instituto Interamericano de Derechos Humanos, 1999. p. 190.

${ }^{12}$ ORGANIZACIÓN DE LAS NACIONES UNIDAS, ONU, Pacto adoptado y abierto a la firma, ratificación y adhesión por la Asamblea General en su resolución 2200 A (XXI), de 16 de diciembre de 1966. Entrada en vigor: 3 de enero de 1976, de conformidad con el artículo 27. Instrumento de Ratificación del Protocolo Facultativo del Pacto Internacional de Derechos Económicos, Sociales y Culturales, hecho en Nueva York el 10 de diciembre de 2008: «Considerando que, para asegurar mejor el logro de los propósitos del Pacto y la aplicación de sus disposiciones, sería conveniente facultar al Comité de Derechos Económicos, Sociales y Culturales (en adelante denominado el Comité) para desempeñar las funciones previstas» $\mathrm{BOE} \mathrm{n} .^{\circ} 48$ de 25 de febrero de 2013.

${ }^{13}$ MARIÑO, F. M., «Avances jurídicos en la protección de los derechos económicos, sociales y culturales dentro del marco de las Naciones Unidas», Revista de Derechos y Libertades, Madrid, Universidad Carlos III-Boletín Oficial del Estado, Año III, Febrero, n. ${ }^{\circ} 6,1998$, p. 94. 
Por último, la diversidad de técnicas de garantía para el desarrollo del modelo de derecho social pone su acento, según los diferentes autores, en la garantía institucional, la garantía jurisdiccional o la garantía social, mediante la movilización constante de los individuos y los grupos portadores de estos intereses y valores. En referencia a la garantía institucional, temática de este trabajo, cuando el reconocimiento jurídico de un derecho social se entiende como un mandato dirigido por el poder constituyente al legislativo y la administración para que actúe positivamente. Según LORA, para el caso de vulneración a la protección de la salud cabría recriminar al legislador y a la administración el que no proporcionen cobertura sanitaria a todos los ciudadanos ${ }^{14}$. En ello consistiría, por lo tanto, el derecho que nos ocupa: en un mandato o desafío lanzado a los poderes públicos para que se pongan manos a la obra y organicen la asistencia sanitaria.

\section{LA RESPONSABILIDAD Y EL SUJETO OBLIGADO EN EL DERECHO A LA ASISTENCIA SANITARIA: SU PERÍMETRO}

\section{A La concreción de lo responsable}

Al recaer en el Estado (los poderes públicos) la responsabilidad sobre los derechos sociales se hace necesaria la formulación de normas secundarias o de organización que se interpongan entre el derecho y la obligación; es decir, entre el sujeto acreedor y el sujeto deudor ${ }^{15} \mathrm{o}$, de otra manera, que sean uno de los niveles como se incorporan los derechos sociales en el Derecho positivo ${ }^{16}$. Eso supone que esas normas ordenan mandar a los poderes públicos, es decir, ordenan realizar conductas positivas tendentes, o bien a crear normas que garanticen derechos subjetivos o bien crear servicios públicos que faciliten o hagan posible una acción promocional positiva en el ámbito concreto. En fin, el acceso a los bienes, servicios y oportunidades destinados a satisfacer las necesidades de salud no es sólo un derecho humano fundamental y la clave para que las personas puedan disfrutar de otros derechos humanos fundamentales. En nuestra $\mathrm{CE}^{17}$, pa-

${ }^{14}$ LORA DEL TORO, P, «El derecho a la protección de la salud», en BETEGÓN CARRILLO J.; LAPORTA SAN MIGUEL F.; PRIETO SANCHÍS L.; DE PÁRAMO ARGÜELLES J. R. (coords.) Constitución y derechos fundamentales, Madrid, 2004, pp. 875-910.

${ }^{15}$ PRIETO SANCHÍS, L., Ley, principios, derechos, Madrid, Dykinson - Instituto de Derechos Humanos «Bartolomé de las Casas», Cuadernos n. ${ }^{\circ}$ 7, 2002 p. 78.

${ }^{16}$ PECES BARBA MARTÍNEZ, G., Ibídem, p. $80 \mathrm{ss}$.

${ }^{17}$ GUTIÉRREZ GUTIÉRREZ I.; ALGUACIL GONZÁLEZ-AURIOLES J., Máster en Derechos Fundamentales UNED - Curso 2011/2012 Asignatura: Concepto de derechos 


\section{Jesús Esteban CÁrcar Benito}

rece que la terminología no ofrece orientación alguna que permita establecer un rasgo distintivo que oponga, entre los derechos reconocidos, los «derechos fundamentales» $\mathrm{y}$ "derechos de los ciudadanos», al menos en términos que puedan ser reconducidos a la sistemática constitucional.

Desde una perspectiva social la asistencia sanitaria es también un elemento decisivo para la construcción de capital humano, a través de la inserción de los individuos en la vida de su comunidad. Comenzando con una perspectiva económica, es un factor esencial para el desarrollo productivo de los países ${ }^{18}$. Para que se cumplan las dos condiciones, los bienes, servicios y oportunidades de salud deben ser distribuidos de modo tal que una cantidad suficiente de personas alcance y conserve un estado de salud que permita generar y mantener el tejido social y la plataforma productiva. Sin embargo, para que las condiciones mencionadas contribuyan a la cohesión social y al desarrollo humano de los países, la distribución de los bienes, servicios y oportunidades, quedaría en el acceso a la salud no solo debe involucrar a un número crítico de personas. Debe ser además equitativa.

RAWLS parte de la idea de una sociedad bien ordenada como sistema equitativo de «cooperación entre ciudadanos razonables y racionales concebidos como libres e iguales, en donde ha de seleccionarse los principios públicos de justicia para la estructura básica de la sociedad ${ }^{19}$. Desde el punto de vista ético la distribución equitativa de

fundamentales en la Constitución española Materiales para el estudio, Bloque 3. Pero más complicado aún resulta identificar los derechos: todos son «derechos» (lo dice el epígrafe del capítulo), y aún «derechos fundamentales» (conforme al epígrafe del Título); y, sin embargo, hay unos que son de nuevo cualificados como «derechos fundamentales», mientras que otros se quedan en «derechos de los ciudadanos»; ¿es que estos últimos no son acaso tan fundamentales? ¿O más bien ocurre que los derechos de esa sección segunda son sólo de los ciudadanos, y nunca de los extranjeros? Lo que está en todo caso claro es que no todos los derechos de la sección primera corresponden siempre y en todo caso, por más que se proclamen como «fundamentales» y no "de los ciudadanos», también a los extranjeros; porque los hay al menos que se refieren expresamente a "los españoles» (arts. 19 y 29) o incluso, con cierto alcance excluyente (art. 13.2), a «los ciudadanos» (art. 23). El principio de igualdad, colocado en el art. 14 como pórtico de este Capítulo, incorpora asimismo un derecho, pero ¿corresponde sólo a los ciudadanos, dado que comienza hablando de «los españoles»? En definitiva, parece que la terminología no ofrece orientación alguna que permita establecer un rasgo distintivo que oponga, entre los derechos reconocidos por la Constitución, los «derechos fundamentales» y "derechos de los ciudadanos», al menos en términos que puedan ser reconducidos a la sistemática constitucional.

${ }^{18}$ ACUÑA, M. C., «Exclusión, protección social y el derecho a la salud», en Unidad de Políticas y Sistemas de Salud Área de Desarrollo Estratégico de la Salud OPSOMS, Revista Panamericana de Salud Pública, marzo 2005, disponible en: http://www. lachsr.org/extension/pdf/exclus-ders

${ }^{19}$ RAWLS J. El liberalismo político, Editorial crítica, Barcelona, 2013, pp. 206 ss. 
los bienes, servicios y oportunidades de salud se inscribe en el marco de la Teoría de la justicia de RAWLS ${ }^{20}$, que plantea que todos los bienes sociales primarios -libertad y oportunidad, ingreso y riqueza, y las bases del autorrespeto- deben ser distribuidos igualmente a menos que la distribución desigual de uno o todos estos bienes favorezca a los menos privilegiados. El segundo principio de la citada teoría establece que los bienes sociales y económicos deben ser organizados para el máximo beneficio de los más débiles.

La búsqueda de equidad es un objetivo central de muchos sistemas de salud en la actualidad y representa un desafío que se extiende más allá del sector salud. La inequidad en la distribución de los bienes y oportunidades de salud y en la utilización de los servicios de salud se manifiesta en la existencia de grupos de personas que no pueden disfrutar de dichos bienes, servicios y oportunidades, es decir, se encuentran excluidos del acceso a los mecanismos de satisfacción de sus necesidades de salud. La exclusión en salud representa la negación del derecho a la salud para estas personas.

En suma, la asistencia sanitaria, como todos los derechos sociales, es un derecho y son las condiciones materiales que hacen posible el ejercicio de las libertades, es decir, permiten que los individuos puedan realizar el plan de vida que deseen; ofrece las circunstancias materiales para el ejercicio de las libertades, incluidas las políticas; y no se les debe hacer depender del estatus de ciudadanía. Esto último no quiere decir que haya que renunciar a la categoría de ciudadanía. La categoría de ciudadanía, a veces, no es la más idónea teóricamente. FERRAJOLI ha mostrado que los derechos que se contienen en la categoría de civiles tienen una naturaleza distinta: algunos son propiamente civiles, otros son libertades y otros son patrimoniales ${ }^{21}$. A diferencia de los derechos de autonomía, que asumen la forma de expectativas negativas frente a las que corresponde el deber de los poderes públicos de no hacer (o prohibiciones), los derechos sociales imponen deberes de hacer u obligaciones, como es el caso de la asistencia sanitaria. En conexión con esto último, ALEXY relaciona los derechos sociales con tres tipos distintos de derechos de prestación: el derecho a protección, el derecho a organización y procedimiento, que equivale a los denominados «derechos liberales» y el derecho a pres-

${ }^{20}$ RAWLS, J., A theory of justice, Mexico, Fondo de Cultura Económica de, 1997, pp. 12 ss.

${ }^{21}$ FERRAJOLI, L. «Iuspositivismo crítico y democracia constitucional», trad. de L. CÓRDOVA y P. SALAZAR, Isonomia, 16, 2002, p. 16. De ahí que en Principia Iuris se hable a veces indistintamente del "paradigma constitucional o garantista», 2011. 
tación en sentido estricto ${ }^{22}$. Así, intentaré encuadrar a la asistencia sanitaria dentro de su perímetro.

\section{B El Perímetro de la responsabilidad: necesidades, bienes y reversibilidad}

El Estado adquiere la obligación de satisfacer esas necesidades básicas, como es la asistencia sanitaria de los ciudadanos por medio de acciones directas o prestando servicios públicos. Los derechos sociales redefinen el rol del Estado y le establecen un perfil distinto: el Estado social. Un Estado que se responsabiliza de sus ciudadanos y que no se muestra ajeno a sus carencias materiales. En el mismo sentido, el derecho a la asistencia sanitaria, puede requerir por parte del Estado hacer hospitales y brindar acceso universal, no obstante, también demanda por parte del Estado obligaciones de no lesión como el de no contaminar el ambiente, prohibir la venta de medicamentos caducos, imponer estándares de calidad a productos o impedir la venta de medicamentos que pongan en riesgo la salud. Los diversos tipos de derechos fundamentales ratifican distintas actitudes y distinta estructuración de los poderes públicos ${ }^{23}$. Como se ha dicho anteriormente, existe una estrecha relación del Estado de Bienestar con los derechos sociales; inclusive es la que le otorga apellido ${ }^{24}$.

Por ello, propongo que se vean a los derechos sociales, entre ellos el de asistencia sanitaria, como derechos fundamentales en el sentido de que tutelan bienes que tienen que ver con «la supervivencia y con el disfrute de las condiciones materiales que posibilitan el ejercicio real de la libertad o de la autonomía política ${ }^{25}$. Esto es lo que define PECES BARBA con su concepción dualista de los derechos Fundamentales, en el sentido de que por un parte son derechos subjetivos del ciudadano frente al Estado, garantizando así un status jurídico de libertad de las personas, y por otra parte, son valores o elementos configuradores y fundamentadores del propio sistema político, lo cual nos revela su carácter integrado, y a la vez transformador del mis-

${ }^{22}$ ALEXY, R. Teoría de los derechos fundamentales, Centro de Estudios Políticos y Constitucionales, Madrid (traducción de Ernesto Garzón Valdés), 2002, pp. 430 ss.

${ }^{23}$ CONTRERAS PELAEZ, F., Derechos Sociales: Teoría e Ideología, Madrid, Tecnos, 1994. p. 47.

${ }^{24}$ FORSTHOFF, E., El Estado en la sociedad industrial, Madrid, Instituto de Estudios Políticos, 1975, p. 265.

${ }^{25}$ PISARELLO, G., Los derechos sociales y sus garantías: elementos para una reconstrucción, Trotta, Madrid, 2007, p. 11. 
$\mathrm{mo}^{26}$. A partir de una perspectiva objetiva PÉREZ LUÑO estima que los derecho sociales, entre ellos la asistencia sanitaria, tienen un carácter redistributivo, son fundamentales y se pueden ver como el conjunto de normas a través de las cuales el Estado lleva a cabo su función equilibradora de las desigualdades sociales; desde un ámbito subjetivo, como la facultad de los individuos y los grupos a participar de los beneficios de la unidad social, es decir derechos y prestaciones por parte del poder público ${ }^{27}$.

En definitiva, lo bienes reconocidos en las constituciones, en nuestro caso la salud, son fundamentales en tanto se reconocen a todas las personas, independientemente de sus rasgos de adscripción, de que sean ciudadanos y de su grado de necesidad. De hecho, son bienes que cobran especial importancia para los miembros más vulnerables de un Estado porque se convierten en la condición de viabilidad para el ejercicio de sus libertades. Por ejemplo, para una persona que se encuentra en una situación de enfermedad, marginación o deficitaria (por lo que hace a las condiciones mínimas vitales de existencia), el derecho social a la asistencia sanitaria resulta de vital importancia porque la protegen de no morir por falta de asistencia médica, y más aún, porque ofrecen condiciones que le permiten mejorar su situación a través de ésta, y la enfermedad, la edad, el sexo, lo que hace es que sus necesidades sean diferentes. Estos factores condicionan y determinan el uso de los bienes primarios para hacer cosas valiosas ${ }^{28}$. Por ejemplo, una persona no asistida puede poseer una cesta mayor de bienes primarios y, sin embargo, tener menos probabilidades de llevar una vida normal (o de alcanzar sus objetivos) que una persona sana que tenga una cesta más pequeña de bienes primarios ${ }^{29}$. Este encuadre de SEN es sumamente significativo porque los objetivos de la asistencia sanitaria están ligados a la función social que cumple la protección a la salud en todas sus dimensiones -preventiva y asistencial-. Para evaluar el grado de bienestar de una persona, el criterio debe ser no sólo la cesta de bienes primarios, sino lo que ésta pueda hacer con esos bienes, es decir, la capacidad que tiene para transformar esos bienes en objetivos. Son, al igual que todos los derechos fundamentales, leyes de protección del más débil -para usar la frase de FERRAJOLI-, ya que en ausencia de ellas regiría la ley del más fuerte. Son expectativas que comportan bienes económicos y en ese sentido son prestacionales, pero también requieren de inmunidades,

${ }^{26}$ PECES BARBA, Teoría de los Derechos fundamentales, Guadiana, Madrid 1973.

${ }^{27}$ PÉREZ LUÑO, E., Los derechos fundamentales, Tecnos, 2007.

28 SEN, A. Desarrollo y libertad, México: Planeta. 2000, pp. 50 ss.

${ }^{29}$ SEN, A., Ibídem. pp. 200 ss. 


\section{Jesús Esteban CÁrcar Benito}

acciones de no lesión por parte del Estado frente a poderes públicos y privados. Son gravosos al igual que todos los derechos, sin embargo, es mucho más costoso proveerlos como programas de asistencia, «sin un proyecto garantista que ponga énfasis en sus particularidades» 30 .

Los derechos sociales llevan aparejados deberes positivos, es decir, todos son en algún sentido prestacionales, como diría ALEXY, "son derechos del individuo frente al Estado a algo que -si el individuo poseyera medios financieros bastantes y si encontrase en el mercado una oferta suficiente- podía obtener también de particulares ${ }^{31}$. Si bien es verdad, al menos en principio, que el legislador tiene una extensísima libertad para estipular en cada momento concreto, mirando fundamentalmente a la situación económica, la holgura de las prestaciones públicas sanitarias gratuitas o bonificadas, así como las circunstancias que han de reunir los titulares de este derecho. Desde este plano, la supresión de determinadas prestaciones: medicamentos del sistema público subvencionado, el aumento de porcentaje de aportación de los ciudadanos o el pase a un sistema de aportación pecuniaria para disfrutar de determinados servicios (transporte sanitario no urgente o prestaciones ortoprotésicas, por ejemplo) se situarían en el marco de opciones de políticas públicas que corresponde limitar, moderar y ejecutar a los poderes públicos, de acuerdo con las prelaciones políticas y las condiciones sociales y económicas de cada momento histórico en concreto. Si bien aparece como un requerimiento constitucional de financiación pública de un núcleo mínimo de prestaciones sanitarias, sea en el marco de la seguridad social sea fuera de ella como servicio público de la sanidad, que implica la necesidad de concretar las prestaciones que son objeto de dicha financiación ${ }^{32}$. Ahora bien, aunque se acepte esa exigencia constitucional, es cierto que el elenco de posibilidades que se extiende al legislador es amplísimo. El margen para decisiones de cobertura básica es muy extenso, dependiente en muy buena medida de las posibilidades económicas disponibles.

Doctrinalmente, se ha aceptado la reversibilidad de los derechos sociales, entre ellos la asistencia sanitaria, pero, aun así, se discute sobre cuáles sean las condiciones y los límites en que ésta pueda

${ }^{30}$ FERRAJOLI L., Garantismo. Una discusión sobre derecho y democracia, trad. de A. GREPPI, Madrid: Trotta, 2006, pp. 99 y ss, del mismo autor Principia iuris. Teoria del diritto e della democrazia, Laterza, Bari, 2007, vol. I, pp. 724 y ss.

${ }^{31}$ ALEXY R. op. cit., p. 482.

${ }^{32}$ CÁRCAR BENITO J. E., "La cartera de servicios y su necesidad dentro de la configuración del derecho a la salud: configuración y categorización», DS, Derecho y Salud. Vol. 24, n. ${ }^{\circ}$ 2, julio-diciembre 2014. 
producirse. A partir de esta configuración constitucional del derecho a la protección de la salud, podemos plantearnos si existe o no algún límite para el legislador ordinario pues, dentro de estos amplísimos márgenes de libertad que nuestro ordenamiento le concede, no es lo mismo no seguir avanzando en la extensión del contenido de este derecho que reducir el contenido de sus prestaciones o excluir a determinados colectivos de ciudadano. El límite sería que el fundamento de la universalización de la asistencia sanitaria pública, como derecho social, se encuentra en el concepto jurídico-filosófico de la persona, en la dignidad que le es inherente en su calidad de ser humano $^{33}$. La pregunta, por tanto, es si puede el Estado adoptar medidas de respuesta a la crisis ignorando sus obligaciones en materia de derechos humanos. ¿Es acaso el derecho a la asistencia sanitaria una mera suntuosidad que la ciudadanía solamente puede ejercitar en épocas de bonanza económica? Los Estados tienen la obligación de adoptar medidas concretas, incluidas las legislativas, administrativas y financieras, que permitan a todas las personas que se encuentran bajo su potestad disfrutar de ellos. Las normas internacionales de derechos humanos, como he indicado, no regulan de forma expresa cómo deben diseñarse o aplicarse las políticas públicas, pero determinan qué elementos deben asegurarse para garantizar que aquellas sean compatibles con las obligaciones respectivas en materia de derechos humanos y ofrecen, además, un marco jurídico definido para la formulación y ejecución de todas ellas, incluidas las económica y las fiscales ${ }^{34}$.

Para FERRAJOLI hay en estos momentos una crisis del Estado en tanto que no resguarda los derechos fundamentales de manera suficiente, llegando a deslegitimarse por esa desprotección. Hay una retroceso en lo público. El paradigma garantista exige que el Estado efectúe sus obligaciones negativas y también las positivas. Por ello, se confronta la crisis del Estado social con la crisis del Estado como institución. Una disminución de partidas presupuestarias de las destinadas a la provisión del Estado del bienestar, envuelve una reducción de la obligación positiva del Estado, es decir, una dejación en su función garante del cumplimiento en los derechos fundamentales sociales y

${ }^{33}$ BELTRÁN AGUIRRE, J L., "La universalización de la asistencia sanitaria en España en el marco de los objetivos de la Unión Europea en materia de salud y del artículo 35 de la Carta de Derechos Fundamentales», Derecho y Salud en la Unión Europea, dirs. Pérez Gálvez, J. F. y Barranco Vela, R, Comares, Granada, 2013.

${ }^{34}$ OSKOZ J., Crisis y recortes en derechos humanos. La defensa de los derechos humanos en tiempos de crisis, La Catarata, 2013. 


\section{Jesús Esteban CÁrcar Benito}

ello determina una deslegitimación ${ }^{35}$, porque los agentes gestores no pueden «decidir» sobre "lo indecidible», que no olvidemos que debe quedar sustraído a la decisión de las mayorías. Es decir, los derechos fundamentales reconocidos en la constitución no son susceptibles de decisión por los gobiernos, pues ello implicaría una desconstitucionalización y por tanto una deslegitimación constitucional del ejecutivo ${ }^{36}$.

\section{LA SUBJETIVIZACIÓN DEL DERECHO A LA ASISTENCIA SANITARIA}

\section{A La protección de la salud y su parte programática}

En nuestro marco jurídico, la concreción constitucional del derecho a la protección de la salud del artículo 43 de la CE se ha contemplado como un mandato dirigido a los poderes públicos para que organicen la asistencia sanitaria, con el elemento causal, como especifica MUÑOZ MACHADO, y adopten el conjunto de medidas necesarias para lograr «la prevención de las enfermedades o la mejora de las condiciones sanitarias generales» ${ }^{37}$. El artículo 43 de la $\mathrm{CE}$, como los demás principios rectores de la política social y económica contiene, por lo tanto, una serie de mandatos dirigidos a los poderes públicos para que hagan efectivas las prestaciones que se definen como contenidos del Estado social y a las que los ciudadanos tendrán derecho a acceder en los términos que establezca la legislación positiva. De ahí que, como se ha dicho de forma expresiva, aunque el artículo 43 no configure un derecho subjetivo constitucional, de él resulta «el derecho a que se establezcan derechos»" que sí serán verdaderos derechos subjetivos de acuerdo con la legislación que los regule.

Entre ellos, estaría el derecho a la asistencia sanitaria. Su contenido, aunque parcial desde la óptica del citado artículo, es, seguramente el más apreciable para los ciudadanos en su conjunto o, al menos, se refiere a los aspectos de la protección de la salud a los que la conciencia social es más sensible y respecto de los que la demanda ha experimentado un incremento espectacular en los últimos años, cuan-

${ }^{35}$ PISARELLO, G. Los derechos sociales en tiempo de crisis. Resistencia y reconstrucción, Barcelona, observatori DESC, 2011.

${ }^{36}$ Ibídem, pp. 16 ss.

${ }^{37}$ MUÑOZ MACHADO, S. La formación y la crisis de los servicios sanitarios, Alinaza, Madrid, 1995.

${ }^{38}$ FERNANDEZ PASTRANA, J.. M, El servicio público de la Sanidad: el marco constitucional, Cuadernos Civitas, Madrid, 1984, p. 62. 
titativa y cualitativamente. En principio, el derecho a la salud presenta dos perfiles delimitables, el primero, integrado por algunas obligaciones tendientes a impedir que la salud sea dañada, ya sea por la conducta terceros -ya sea el Estado u otros particulares- (obligaciones negativas), o por otros factores controlables -tales como epidemias, prevenir enfermedades evitables, a través de campañas de vacunación- (obligaciones positivas). El segundo perfil está integrado por otras obligaciones tendientes a asegurar la asistencia médica una vez producida la afectación a la salud denominadas habitualmente como "derecho a la atención o asistencia sanitaria», cuyo contenido implica, entre algunas prestaciones, la complejísima tarea de planificación y previsión de recursos presupuestarios necesarios para llevar a cabo la satisfacción de los requerimientos de salud correspondientes a toda la población ${ }^{39}$.

En este sentido, diversos autores sostienen que el derecho a la protección de la salud no es un derecho exigible por considerarlo una norma o principio programático. Al respecto definimos a las normas o principios programáticos como «aquellas que establecen simplemente las directivas de acción, de las cuales no deberá apartarse en el futuro el legislador ordinario, el cual se encuentra obligado a aplicar concretamente las citadas disposiciones a la mayor brevedad posible, las que, por otra parte, deben ser observadas por la autoridad administrativa en el ejercicio de sus facultades discrecionales. Los contenidos de estos derechos implican por lo general un resultado concreto (salud, vivienda, alimentación), que en caso de no darse anulan completamente su existencia ${ }^{40}$. En el mismo sentido, podemos afirmar que «el carácter declarativo de las normas programáticas conduce a que no sean accionables, o sea que no se puedan hacer valer en juicio. El ciudadano no tiene derecho a la tutela jurisdiccional para que la autoridad obligue coactivamente al Estado a que haga efectiva aquí y ahora una norma programática. Las normas programáticas son normas impropias, porque no están revestidas de coercibilidad; no pueden hacerse cumplir por la fuerza ni pueden llevarse al órgano jurisdiccional, como en el caso de las normas que otorgan derechos individuales y buena parte de los derechos sociales» ${ }^{41}$.

${ }^{39}$ ABRAMOVICH, V.; COURTIS, C., El derecho a la atención sanitaria como derecho exigible, publicado en La Ley, Tomo D, 2001, pp. 22-29.

${ }^{40}$ BISCARETTI DI RUFFIA, P., Introducción al Derecho Constitucional Comparado. Las formas de Estado y las formas de gobierno. Las Constituciones Modernas, México, D. F., Fondo de Cultura Económica, 1. ${ }^{a}$ edición española, 1975, p. 322.

${ }^{41}$ RUIZ MASSIEU, J. F., Cuestiones de Derecho Político (México-España), Instituto de Investigaciones Jurídicas, México D. F., UNAM, primera edición, 1993, p. 59. 


\section{Jesús Esteban CÁrcar Benito}

Sin embargo, al señalar el derecho a la protección de la salud, algunos autores van más allá al afirmar que «se trata de derechos vacíos de contenido, que campean en nuestros textos constitucionales a manera de simples expresiones ideales, sin llegar siquiera a constituirse en normas programáticas, pues no consigna en sus fórmulas consagrables ningún programa a seguir» ${ }^{42}$. En esta misma corriente de pensamiento algunos afirman «que el proclamado -derecho a la protección de la salud- no es tal y auténtico derecho subjetivo, a pesar de la expresión que se utiliza, sino un mero principio informador o rector de la política social, que debe ser, eso sí, reconocido, respetado y protegido y que informará la legislación positiva, la práctica judicial y la actuación de los poderes públicos ${ }^{43}$. Estamos ante lo que se denomina una guía de conducta, que no es necesariamente un mandato, sino que comprende una declaración de lo que es bueno y lo que es malo, lo correcto y lo incorrecto. De aquí la necesidad de su desarrollo posterior, de esos reenvíos que abrevia la guía de conducta, los valores principales, en mandatos (ordenes, prohibiciones) y sanciones. En pocas palabras, el art. $43 \mathrm{CE}$ reenvía a la ley para la fijación del contenido de los derechos y reenvía a los tribunales para la concreción del contenido de tales derechos. Es por su naturaleza, una norma de definición de valores principales y, en consecuencia, una norma de reenvíos ${ }^{44}$.

Por último, estaría la corriente que adscribe el derecho a la protección de la salud, la asistencia sanitaria, al grupo de los derechos económicos, sociales y culturales. Para algunos autores, la principal característica de estos derechos es la progresividad ${ }^{45}$ o condicionamiento económico, que en principio constituiría la medida de exigibilidad ${ }^{46}$ (incluyendo la del derecho a la protección de la salud) y que con frecuencia se utiliza como pretexto para ocultar evidentes incumplimien-

${ }^{42}$ MARTÍNEZ BULLÉ-GOYRI, V., «El Derecho a la salud como un derecho humano", Seminario Salud y Derechos Humanos, México D. F, Fondo editorial de la Comisión Nacional de Derechos Humanos, primera edición, 1991, pp. 45-48.

${ }^{43}$ FERNÁNDEZ PASTRANA, J. M., op. cit., p. 60.

${ }^{44}$ NIETO GARCÍA, A., "Peculiaridades jurídicas de la norma constitucional», Revista de Administración Pública, RAP, n. ${ }^{\circ}$ 100-1002, enero-diciembre, 1983, pp. 371-414.

${ }^{45}$ Es el cumplimiento paulatino y creciente de los derechos humanos de carácter económico, social y cultural, condicionado por los recursos económicos y técnicos con que cuenta cada uno de los Estados.

${ }^{46}$ MORALES ACHÉ, P. I., Tesina: La Salud y los Derechos Humanos, Puebla (Mexico), Universidad de las Américas, A. C., 1993, pp. 7-8. Para el autor, el concepto de política pública incluye la definición e instrumentación de programas de gobierno, la deliberación parlamentaria y la construcción del derecho a través de resoluciones judiciales. 
UNA REFLEXIÓN SOBRE EL DERECHO A LA ASISTENCIA SANITARIA...

tos aduciendo que se debe a la falta de recursos o para encubrir la inadecuada distribución de los recursos existentes, por lo que hay una íntima vinculación entre la satisfacción del derecho a la protección de la salud y las políticas públicas de salud, ya que estas últimas van a determinar en una prelación de importancia, los aspectos del derecho a la protección de la salud que van a ser atendidos prioritariamente. Si bien es cierto, que la regla general es la progresividad, hay determinadas circunstancias en donde tal derecho es de realización inmediata ${ }^{47}$. En este sentido, el artículo 53.3 de CE nos indica que el capítulo III del Título I donde está contenido el derecho a la protección a la salud, como principio rector de la política social y económica, dice «informarán», expresión ésta que no debe conducir a una interpretación restrictiva de su significado, «la legislación positiva, la práctica judicial, y la actuación de los poderes públicos, pudiendo ser alegados ante la jurisdicción ordinaria de acuerdo con lo que dispongan las leyes que lo desarrollen».

Y GARCÍA DE ENTERRÍA afirma que «... todos los sujetos públicos o privados, en cuanto vinculados a la Constitución y llamados a su aplicación... deben aplicar la totalidad de sus preceptos sin posibilidad alguna de distinguir entre artículos de aplicación directa, y otros meramente programáticos, que carecerían de valor normativo... (-ya que si bien-) no todos los artículos de la Constitución tienen un mismo alcance y significación normativas... todos, rotundamente, enuncian efectivas normas jurídicas... sea cual sea su posible imprecisión o indeterminación... es un reconocimiento preciso de que los principios constitucionales... son algo más que meras normas -programáticas-, en el sentido tradicional que les negaba todas aplicación judicial» ${ }^{48}$. Del hecho de que los artículos en el capítulo III CE no encarnen derechos subjetivos "genuinos» no cabe declarar la ausencia de valor normativo de tales artículos, pues en todo caso funcionan como « principios generales del Derecho cuyo valor normativo está fuera de toda porque deben inspirarla legislación positiva, la práctica judicial y la actuación de los poderes públicos» ${ }^{49}$.

${ }^{47}$ PARRA CORTÉS, L., Tesina: EL deber de progresividad como garantía de los derechos sociales; Director Dr. Francisco Javier Ansuátegui Roig Instituto de Derechos Humanos «Bartolomé de las Casas» Getafe -Septiembre 2012-.

${ }^{48}$ GARCÍA DE ENTERRÍA, E., La Constitución como norma y el Tribunal Constitucional, Madrid, Civitas,1988, pp. 68-69.

${ }^{49}$ MENÉNDEZ REXACH A. «El derecho a la asistencia sanitaria y el régimen de las prestaciones sanitarias públicas, DS: Derecho y salud, Vol. 11, N. ${ }^{\circ}$ Extra 1, 2003 (Ejemplar dedicado a: XI Congreso de Derecho y Salud: "Nuevos retos del Sistema Nacional de Salud»), 2003, pp. 15-36. 


\section{Jesús Esteban CÁrcar Benito}

Ante esta regulación, nuestra doctrina ha señalado que los principios vienen caracterizados por tener un valor interpretativo, una eficacia restrictiva y una eficacia habilitadora. Pero el problema de fondo planteado es el grado de vinculación de los poderes públicos respecto de estos principios. Acerca de esto, creo que su presencia, como derecho a la salud, consecuencia directa de la declaración del Estado social ${ }^{50}$ y democrático de Derecho, no puede conducir a una actitud abstencionista por parte de los mismos, sino más bien exigen una actitud positiva, cuestión esta ya debatida, de los poderes públicos que deben puntualizar dichos principios, pues su cumplimiento no puede ser diferido indefinidamente aunque sí demorado ${ }^{51}$. Al margen de todo ello, en la medida en que el enfoque es el propio de un análisis iusfilosófico, los principios rectores suponen un contenido constitucional mínimo que debe ser realizado por los poderes públicos, especialmente por parte del legislador, pero nada impide que éstos en su actuación, vayan extendiendo la asistencia sanitaria como prestación que es.

\section{B Efectividad, expectativa y derecho público subjetivo}

Por tanto, los llamados derechos sociales, entre ellos la asistencia sanitaria, poseen, a mi juicio, los caracteres propios de los verdaderos derechos, puesto que no carecen de la aptitud para la efectividad, son jurisdiccionalmente justificables, aunque su eficacia inmediata queda recortada y condicionada de tal modo por los factores políti-

${ }^{50}$ PAREJO ALFONSO, L. afirmara que «la legitimidad de la actuación estatal se mide... principalmente en el Estado actual por su capacidad de conseguir y mantener unas determinadas -condiciones de vida- (vid. Estado social y Administración pública, Civitas, Madrid, 1983, pp 20 ss.), y que DE CABO MARTIN, C. considerara prevalente la legitimidad del elemento Estado social con respecto al complejo (vid. «Estado social y democrático de Derecho» en Teoría histórica, II, Barcelona, Promociones y Publicaciones Universitarias, PPU, 1993, pp. 332)

${ }^{51}$ SÁNCHEZ AGESTA, L., Sistema político de la Constitución española de 1978: ensayo de un sistema: (diez lecciones sobre la Constitución de 1978), Madrid, Editora Nacional, 7. ${ }^{\text {a }}$ ed., 1994, p. 188 ss. Vid. también, BASILE, S. "Los valores superiores, los principios fundamentales y los derechos y libertades públicas», en PREDIERI A.; GARCÍA DE ENTERRÍA E., La Constitución española de 1978 / estudio sistemático dirigido, Madrid: Civitas, 1980.pp 253 ss. Vid. DE ESTEBAN, J.; LÓPEZ GUERRA, L.; ESPÍN, E.; GARCÍA MORILLO, J.; PÉREZ TREMPS, P., El régimen constitucional español, Barcelona, Labor, 1980-1982, pp 20-50. Vid. MURILLO FERROL F.; RAMÍREZ JIMÉNEZ. M., Ordenamiento constitucional de España, Madrid, S. M., 1980. Vid. DE OTTO, I., «Introducción», en BASTIDA, F. J; PUNSET, R.; DE OTTO, I (coords.), Lecciones de Derecho Constitucional, Oviedo, Guiastur Ediciones, 1980, pp. 15 ss. Vid. PECES-BARBA G.; PRIETO SANCHIS L., La Constitución española de 1978: un estudio de derecho y política, Valencia, Fernando Torres-Editor, 2. ${ }^{a}$ ed. 1984, pp. 286-291. 
cos, que su mismo contenido varía de un Estado a otro, en función del nivel alcanzado por el desarrollo económico y en función del orden de prioridad que se asigne a la realización de tales derechos. La postura encuentra correspondencia en la doctrina que sostiene que las disposiciones normativas en que se proclaman los derechos sociales llegan a ser auténticas normas jurídicas aplicables, y no simples principios programáticos con una eficacia ético-política meramente directiva. Ahora bien, la respuesta a su naturaleza puede ser solucionada desde diferentes fórmulas doctrinales. De un lado, la posición negadora del carácter de verdaderas normas jurídicas para los derechos sociales, y, por lo tanto, justificadora de una falta de protección jurisdiccional; y de otro lado, la posición que reconoce carácter normativo a los derechos sociales y por tanto exige su defensa y protección judicial ${ }^{52}$. En otras palabras, se trata de reconocer que los derechos sociales gozan de tutela, pero no de la forma como la tienen los derechos civiles. En realidad los derechos sociales se encuentran en un período de transición ${ }^{53}$.

De ahí, dado que los derechos sociales, entre ellos la asistencia sanitaria, han sido englobados en la mayoría de las constituciones, solo hace algo más de cincuenta años, cabe también suponer que estos aspectos también se irán desarrollando con el transcurso del tiempo. En efecto, se puede advertir un notable progreso en este sentido

52 En este sentido, CASTRO CID, B., (vid. Los derechos económicos, sociales y culturales: análisis a la luz de la teoría general de los derechos humanos, León, Servicio de publicaciones Universidad de León, 1993, pp. 74-101) señala que mientras los derechos civiles y políticos se dirigen a un hombre-individuo en su razón de ser abstracto, universal e inmutable, los derechos económicos, sociales y culturales conciben a un hombre histórico concreto. La aparición de estos derechos se acompaña, pues, de un profundo cambio en las condiciones sociales: tanto en la estructura social y de poder, como en los planteamientos en que se plasma la mentalidad política. Para De Castro, antes y después de cualquier reconocimiento por parte de las legislaciones históricas, los derechos económicos, sociales y culturales, al igual que los otros derechos humanos, han de ser entendidos como potestades relativas a la propia existencia y actuación, que corresponden a los sujetos humanos por el simple título de su modo de ser humano y con independencia de los condicionamientos existenciales de raza, sexo, nacionalidad, religión, etc. Y esto sobre su afirmación de que «son derechos humanos aquellas exigencias o expectativas existenciales del hombre en cuanto tal que se imponen a la razón como atribuciones que no pueden faltar en ningún ordenamiento jurídico» y que el Estado está obligado a garantizar.

${ }^{53}$ RUIZ MIGUEL, A., "Derechos liberales y derechos sociales», Doxa Cuadernos de Filosofia del Derecho, Vol. 2, n. ${ }^{\circ} 15-16,1994$, pp. 670-671. Podemos señalar con el autor que «el problema de la tutela judicial efectiva de los derechos fundamentales más, parecería que, incluso en sistemas jurídicos como los europeos-occidentales, obliga a denunciar el déficit de protección de muchos de los derechos sociales como única opción frente a quienes les niegan el carácter de derechos precisamente por la ausencia de dicha tutela. 


\section{Jesús Esteban CÁrcar Benito}

en los últimos años. En la actualidad, es habitual que cada uno de los derechos sociales abstractos se correlacionan con deberes de mayor precisión. Por ello, la propuesta de redefinición del concepto de derecho subjetivo planteada por FERRAJOLI, se inspira precisamente, en la exigencia de resolver este tipo de problema. Para tal redefinición, es aplicado el término expectativa, antes citado, por otro lado, ya identificado como equivalente a "pretensión», en su definición; si bien la noción de expectativa tiene un alcance mucho más extenso ${ }^{54}$. En su sentido más habitual, expectativa es la previsión de lo que posiblemente puede ocurrir; es decir, relacionado con la redefinición de derecho subjetivo, el término adquiere un específica representación normativa. El derecho de un sujeto no es otra cosa que una expectativa de no sufrir lesiones o de tener algunas prestaciones, a cargo de otro sujeto, relativas a un interés del primero. Naturalmente, la expectativa del derecho puede no enlazar con lo que pueda ocurrir, resulta prácticamente ineludible una falta de conexión entre las dos. La amplitud de la discrepancia entre los dos tipos de expectativas mide el grado de eficacia del derecho. El empleo del término derechos supone calificar las exigencias de la sociedad y no intereses individuales. En un sentido opuesto, ATRIA destaca la naturaleza política de las expectativas sociales, poniendo en duda su carácter de derechos subjetivos por considerarlas no susceptible de exigibilidad ${ }^{55}$.

Ahora bien, he referido a los derechos sociales subjetivos en sentido estricto o derechos correlacionados con una obligación (mayormente) de hacer. La obligación de hacer que es contenido de la mayoría de nuestros derechos, en nuestro caso la asistencia sanitaria, puede consistir, de un lado, en la prescripción de lograr un objetivo o alcanzar cierto grado de cosas. Un derecho social, como es este, de otro lado está correlacionado con obligaciones de realizar una acción, la asistencia sanitaria, y podrían abrirse camino por un cierto ordenamiento jurídico como reglas de acción. Por tanto, ello significa que configurar, sin más, el derecho a la asistencia sanitaria no articula el fin. Los derechos exigen garantías idóneas, que deben ser establecidas $\mathrm{y}$ hechas valer eficazmente por el mismo ordenamiento que atribuye los derechos. Desde este punto de vista, la existencia de «derechos sin garantías» parece una especie de aporía dentro de un ordenamiento, que, por un lado, crea, expectativas normativas, y por otro lado, las ignora (o no las satisface adecuadamente). Pero, el derecho a la asistencia sanitaria, incluso entendido sin garantías, no puede ser consi-

${ }^{54}$ FERRAJOLI, L., «Expectativas y garantías: primeras tesis de una teoría axiomatizada del Derecho», Doxa, n. ${ }^{\circ} 20,1997$, pp. 226 ss.

${ }^{55}$ ATRIA. F. «¿Existen derechos sociales?», Discusiones n. ${ }^{\circ} 4$, pp. 15-59. 
derado inexistente, existe en cuanto surge establecido (o afecto, como es el caso actual), por una norma positiva, los derechos «de papel» no son no derechos, sino que es tarea de la teoría identificarlos, y proponer la solución a las aporías en qué consisten ${ }^{56}$.

El derecho a la asistencia sanitaria surge, por lo tanto, como un derecho público subjetivo dada la posibilidad de su exigibilidad. Si la primera pregunta fuera: ¿A quién obliga el derecho a la asistencia sanitaria? La naturaleza de los derechos sociales nos muestran como relevante un tema que de alguna manera se ha señalado tangencialmente en párrafos anteriores: la responsabilidad de los terceros en el esquema de los derechos sociales. Ya PECES BARBA señalaba que los particulares pueden estar a cargo de la prestación de un derecho social $^{57}$. También resaltamos que los derechos sociales gozan de una «doble cara» porque se hacen valer tanto hacia los poderes públicos como en las relaciones entre particulares ${ }^{58}$, que hay detrás de estas argumentaciones es el rasgo de que los derechos sociales no se reducen a una simple obligación del Estado, sino también que involucra a los particulares.

Así, dentro de los ordenamientos jurídicos nacionales hay notables avances sobre la tutela judicial efectiva de los derechos sociales ${ }^{59}$, como he señalado Tampoco es ajeno a este proceso el ámbito internacional en el que, si bien, se reconocen los limitados recursos con que cuentan los Estados para cumplir sus obligaciones, no es óbice para excusar la tutela que ejercen los órganos de control internacional ${ }^{60}$.

${ }^{56}$ BOVERO, M., en «Derechos fundamentales y democracia en la teoría de Ferrajoli. Un acuerdo global y una discrepancia concreta», en De Cabo, A.; Pisarello, G. (edirs.), Los fundamentos de los derechos fundamentales, Luigi Ferrajoli, Barcelona, Editorial Trotta, 2005, pp. 226-227.

${ }^{57}$ PECES BARBA MARTÍNEZ, G., Derechos sociales y positivismo jurídico, Cuadernos Bartolomé de las Casas, n. ${ }^{\circ} 11$, Madrid, Dykinson, 1999, pp. 20 ss.

${ }^{58}$ CASCAJO CASTRO, J. L., La Tutela Constitucional de los derechos sociales, Madrid, Centro de Estudios Constitucionales 1988, pp. 58 ss.

59 PEREZ LUÑO, A. E, Derechos Humanos, Estado de Derecho y Constitución, Madrid, Tecnos, 2003, p. 92. Estima el citado profesor que «debe también rechazarse la afirmación de que mientras los derechos de libertad se benefician de la tutela constitucional directamente, los derechos sociales no pueden ser objeto inmediato de tal tutela. Si la constitución puede formular positivamente los derechos sociales puede también tutelarlos en igual medida que a los demás derechos en ellas proclamados. Así, si se proclama por vía constitucional y con carácter general para todos los trabajadores el derecho a la asistencia sanitaria podría impugnarse como anticonstitucional cualquier disposición de rango inferior que excluye a un determinado grupo de trabajadores de ese beneficio, al igual que una ley que suprimiera la libertad de culto o el derecho de sufragio».

${ }^{60}$ ORGANIZACIÓN DE LA NACIONES UNIDAS, ONU, Instrumento internacional de derechos humanos, Recopilación de las observaciones generales y recomendacio- 


\section{Jesús Esteban CÁrcar Benito}

Un balance sobre el tema de la tutela de los derechos sociales nos lleva admitir que tienen dificultades para su cumplimiento, pero que hay evidencias claras -tanto en los ordenamientos internos como internacionales- de este proceso se viene revertiendo a favor de su recto ejercicio. El derecho a la asistencia sanitaria no puede ser una pretensión moral. Es frente a las condiciones concretas que el Estado puede y debe garantizar este derecho. El derecho a la asistencia sanitaria se considera como tal frente a unas condiciones que el Estado puede modificar y precisamente, porque existe es posibilidad de modificación, es posible de hablar de exigibilidad.

\section{LA UNIVERSALIZACIÓN DEL DERECHO SUBJETIVO A LA ASISTENCIA SANITARIA: EL LARGO PROCESO DEL MARCO NORMATIVO Y SUS PROPUESTAS}

Los derechos sociales en general, y el de la asistencia sanitaria en particular, llevarían aparejado, por tanto, un deber genérico consistente en que se diseñe un esquema institucional de provisión universal de bienes y servicios básicos, sistema que todos los individuos habrían de contribuir de acuerdo con su capacidad económica. Quiebra así un derecho social por el Estado, poderes públicos, que no se preocupa en asegurar dichas prestaciones, pero también quienes se resisten a participar en tal organización social o quienes apoyen o sustenten un régimen político en el que no se garantiza a los bienes y derechos que los derechos humanos protegen. ${ }^{61}$ El acceso a una atención sanitaria integral, de calidad, en condiciones de equidad y de universalidad, es un derecho fundamental de toda persona. La asistencia sanitaria, en consecuencia, estaría dentro de la definición de derechos fundamentales que propone FERRAJOLI. «todos aquellos derechos subjetivos que corresponden universalmente a todos los seres humanos en cuanto dotados del status de personas, de ciudadanos o personas con capacidad de obrar». Es precisamente el rasgo formal que permite identificar esta categoría es el carácter universal de la imputación.

nes generales adoptadas por órganos creados en virtud de tratados de derechos humanos, GE.04-41305(S) 010604, 070604, HRI/GEN/1/Rev.7 12 de mayo de 2004, pp. 8-183. A modo de ejemplo podemos mencionar el pronunciamiento del Comité de Derechos Económicos, Sociales y Culturales de Naciones Unidas sobre el tema: «el Comité reconoce que los programas de ajuste son muchas veces inevitables y que a menudo suponen un elemento importante de austeridad. Ahora bien, en tales circunstancias, los esfuerzos por proteger los derechos económicos, sociales y culturales más fundamentales adquieren una urgencia mayor, no menor»

${ }^{61}$ FERNÁNDEZ PASTRANA, J. M., op. cit., pp. 56-62. 
Efectivamente, velar por el cumplimiento del derecho universal a la protección de la salud de la ciudadanía constituye una exigencia moral, como hemos señalado. Más aún cuando quienes se ven privados de una asistencia digna sufren situaciones de vulnerabilidad, riesgo de exclusión social, carecen de suficientes recursos económicos o viven en condiciones de irregularidad administrativa. En estos casos, la universalización de la atención no solo elimina barreras al acceso a la sanidad y contribuye al bienestar físico y mental de las personas, sino también remueve algunos de los principales obstáculos sobre los que se asienta la desigualdad social.

La sanidad pública nació en España como un seguro social, vinculado a la cotización del trabajador. El modelo se transformó después de la Transición hacia una universalización de la asistencia sanitaria manteniendo su gratuidad. Es decir, desde los años 80, se ha ido avanzando lentamente hacia otra concepción de la salud: no una contraprestación a lo cotizado, sino un derecho ciudadano universal. De ahí, su carácter como "fundamental», un derecho que, «independientes del contenido de las expectativas que tutelan», se caracteriza por la forma universal de su imputación, «entendiendo universal en el sentido lógico y no valorativo de la cuantificación universal de la clase de sujetos que, como personas, como ciudadanos o capaces de obrar, sean sus titulares ${ }^{62}$. Para ello, se amplío el ámbito subjetivo del derecho a la protección de la salud con fondos públicos, que fue profundamente modificado mediante el «Real Decreto-ley 16/2012, de 20 de abril, de medidas urgentes para garantizar la sostenibilidad del Sistema Nacional de Salud y mejorar la calidad y seguridad de sus prestaciones», no sólo desde un punto de vista conceptual, a través de la figura del «asegurado» como titular del derecho a la asistencia sanitaria, sino también por la restricción de las personas que hasta entonces disponían de cobertura sanitaria pública. Así, la Ley General de Sanidad, de 28 de abril de 1986 (LGS), en desarrollo del artículo 43 de la CE, creó el Sistema Nacional de Salud y declaró como titulares del derecho a la protección de la salud a los españoles y extranjeros que tuvieran su residencia en territorio nacional.

Para algunos, el Real Decreto, antes citado, supone una modificación que retrotrae al sistema sanitario a un modelo de aseguramiento similar al vigente en los años setenta y principios de los ochenta, antes de la aprobación de la introducción normativa del año 86. La sanidad deja de ser pública, universal y gratuita para todos los ciudada-

${ }^{62}$ FERRAJOLI, L., Los fundamentos de los derechos fundamentales, Madrid, Trotta, 2007, pp. 290 ss. 


\section{Jesús Esteban CÁrcar Benito}

nos y se convierte en una sanidad solo para los asegurados y la beneficencia, concepto ya superado. La pretensión era ampliar, progresivamente, el ámbito de cobertura a toda la población y garantizar las prestaciones en condiciones de igualdad efectiva para lo que ya anunciaba una extensión gradual de la asistencia sanitaria gratuita, extensión que cuatro años después tuvo un importante exponente en el Real Decreto 1088/1989, que reconoce el derecho a la protección a la salud con fondos públicos a personas sin vinculación con la Seguridad Social cuando sus ingresos fueran inferiores a un determinado umbral. En tal caso, el acceso, aunque «libre», no se produciría en condiciones de «igualdad efectiva» como quiere el art. 3.2 de la LGS. De lo contrario, existiría una vulneración del principio de igualdad consagrado en el art. 14 de la CE y la conculcación del mandato constitucional al legislador de remover todos los obstáculos que hacen impracticable el ejercicio de los derechos (art. $43 \mathrm{CE}$, entre otros) reconocido en el art. 9.2. CE. Un precepto que compromete la acción de los poderes públicos, a fin de que pueda alcanzarse la igualdad sustancial entre los individuos, con independencia de su situación social. (STC 39/1986, de 31 de marzo). Es cierto, sin embargo, que esa igualdad efectiva no implica necesariamente la financiación pública íntegra de las prestaciones en todos los casos. Frente a ello, se podría objetar que un tal sistema discrimina positivamente a los usuarios de mayor capacidad económica, que reciben gratuitamente unas prestaciones cuyo coste podrían satisfacer sin quebranto patrimonial grave. En suma, económicamente la separación entre atención sanitaria y Seguridad Social no se consuma en 1986, hasta tal punto que en 1994, cuando se publicó un nuevo Texto Refundido de la Ley General de Seguridad Social, R. D. Legislativo 1/1994, de 20 de junio, ha de realizarse todo un ejercicio de perspicacia jurídica para incluir la asistencia sanitaria como parte del Sistema de Seguridad Social, pero al mismo tiempo dejarla sin regulación dentro de la legislación refundida de dicho Sistema.

Este sistema de cobertura universal y pública se confirmó en la Ley 16/2003, de Cohesión y Calidad del Sistema Nacional de Salud (LCCSNS), así como en la Ley Orgánica 4/2002 que reconoció a los extranjeros la asistencia sanitaria en las mismas condiciones que a los españoles con el mero requisito del empadronamiento. Por su parte, la Ley 49/1998, de 30 de diciembre, de Presupuestos Generales del Estado para 1999 dispuso la financiación pública de la asistencia sanitaria a través de transferencias presupuestarias a las comunidades autónomas, disgregando aquella, por tanto, de las contribuciones a la 
Seguridad Social ${ }^{63}$. Con ella se logró conectar la titularidad universal del derecho a la protección de la salud con la gratuidad de la asistencia sanitaria pública, culminando la pretensión de la LGS de universalización plena de la asistencia sanitaria con fondos públicos.

Así y todo, existe, por tanto, en primer lugar, un núcleo básico indisponible para el legislador en materia de derechos sociales cuyo quebrantamiento supondría transgredir el modelo constitucional y dinamitar lo que supone la configuración de España como «Estado Social y Democrático de Derecho». Esto engarza con la proclamación como valores superiores (artículo 1.2) de la «justicia e igualdad». Esta última resulta claramente rota cuando, por las medidas de los gobernantes, se ahonda la brecha de la desigualdad ${ }^{64}$. Asimismo, en segundo lugar, deben señalarse los bordes mínimos, la «dignidad» de las personas, la cual constituye "fundamento del orden político y de la paz social» (artículo 9.1 CE). En consecuencia, al sujetar, por tanto, la universalización o generalización del derecho a la asistencia sanitaria con la financiación pública de las prestaciones, el legislador señaló el reto, pero tanto más loable cuanto que con ella se persigue claramente la efectividad real del derecho y no sólo su afirmación en el plano formal, como he señalado. En fin, sólo un derecho fundamental a la asistencia sanitaria impondría como vínculos normativos tanto a las decisiones de las mayorías como al libre mercado, y a toda otra instancia que pudiera poner en riesgo su protección ${ }^{65}$. Sin embargo, trasciende una percepción insuficiente de la naturaleza de estos derechos «el entenderlos simplemente como restricciones al poder». Esto porque junto con su dimensión restrictiva, "existe también una dimensión de aseguramiento, que exige que los Estados se esfuercen por lograr el máximo desarrollo de los derechos humanos de quienes habitan en su territorio y por prevenir y reparar las vulneraciones que pueden provenir [tanto] de sus propios agentes como de los particulares ${ }^{6}{ }^{6}$. De poco serviría, en efecto, la facultad generalizada del derecho a la asistencia si el titular tuviera que abonar el coste del servicio y careciera de recursos para ello. La libertad de acceso, sin

${ }^{63}$ La citada Ley sintetizó la separación de fuentes de financiación entre el Sistema Nacional de Salud y la Seguridad Social. En el mismo proceder, la Ley 33/2011, de 4 de octubre, General de Salud Pública, supuso el último paso para desvincular la sanidad de la Seguridad Social.

${ }^{64}$ LÓPEZ-MEDEL BASCONES, J., «Límites jurídicos del Estado de Bienestar», consultado el 12 de mayo de 2015 en www.abogacia.es

${ }^{65}$ MELLO, C. A., Democracia constitucional e direitos fundamentais. Porto Alegre: Livraria do Advogado, 2004, p. 107

${ }^{66}$ OTTAVIANO, S. "Garantías penales y derechos humanos». en Cianciardo, Juan (coordinador), La interpretación en la era neoconstitucional. Una aproximación interdisciplinaria, Buenos Aires, Ábaco de Rodolfo Depalma, 2006, p. 430. 


\section{Jesús Esteban CÁrcar Benito}

financiación pública, y, por tanto, con obligación de pagar el coste de las prestaciones recibidas, impediría, de hecho, el acceso a los potenciales usuarios carentes de recursos. En consecuencia, con la LGS, la asistencia sanitaria huye de ser una prestación contributiva del Sistema de Seguridad Social para convertirse en un derecho de todos los ciudadanos residentes en España, y por tanto la pertenencia o no a aquel sistema, alta y afiliación al mismo, y por extensión, la de la persona dependiente de afiliado y en alta, desaparece. Se esté o no en alta en un régimen de Seguridad Social y se dependa o no económicamente de una persona en alta, se tiene derecho a la asistencia sanitaria y por tanto al reconocimiento administrativo de este derecho con carácter personal y propio.

En este razonamiento, hay una precipitación por la subjetivación de la sanidad, esto es, el cambio de perspectiva desde lo objetivo (el sistema o el instrumento) a lo subjetivo -los derechos de quienes comprendidos dentro del art. 3 de la LCCSNS-, viene exigida no tanto como consecuencia de los derechos fundamentales, que desde luego es evidente que están presentes a lo largo de la evolución normativa del régimen de la sanidad como derechos fundamentales existentes, sino como consecuencia de la culminación de un proceso de reconocimiento en esta materia, a veces desde la propia descentralización del Estado ${ }^{67}$.

En ese devenir, quedaron protegidos colectivos que hasta entonces no gozaban del derecho a la asistencia sanitaria con cargo a fondos públicos: los parados que hubieran agotado el derecho a la prestación o subsidio de desempleo, aquellas personas que nunca habían cotizado a la Seguridad Social y que tampoco podían recibir asistencia sanitaria en el Sistema Nacional de Salud porque sus ingresos eran superiores a los previstos en el Real Decreto 1088/1989, y los trabajadores por cuenta propia o profesionales que no estuvieran incluidos en el régimen especial de la Seguridad Social de trabajadores autónomos. Con la disposición adicional sexta de la Ley General de Salud Pública se alcanzaba, por fin, la coherencia de un Sistema Nacional de Salud financiado a través de impuestos y desvinculado de las cotizaciones a la Seguridad Social. Sin embargo, el Real Decreto 16/2012 ha vuelto a vincular el derecho a la asistencia sanitaria pública gratuita con la Seguridad Social, retrocediendo en el largo camino recorrido hasta entonces. Consagra de vuelta la figura del

${ }^{67}$ DE LA QUADRA SALCEDO, T. «Igualdad de los pacientes y cohesión del Sistema Nacional de Salud», en Luciano Parejo, Alberto Palomar, Marcos Vaquer, (coords) La reforma del Sistema Nacional de Salud, Cohesión y Calidad del Sistema Nacional de Salud, Madrid, Marcial Pons,2004, p. 12. 
«asegurado» como sujeto del derecho a la protección de la salud. Paradójicamente extiende la condición de asegurado a personas que no tienen ninguna relación con la Seguridad Social siempre que sus ingresos no superen un límite que se determinará reglamentariamente, pero, por otro lado, exige la suscripción de un convenio especial a quienes no puedan acceder a la condición de asegurado, lo que es contradictorio con un sistema sanitario público no financiado por cotizaciones a la Seguridad Social.

El Real Decreto-ley 16/2012, pues, vino a derogar tácitamente los preceptos de la Ley General de Salud Pública sobre extensión de la asistencia sanitaria, dejando sin cobertura sanitaria directa a los profesionales y a todos aquellos que no tengan ningún vínculo con la Seguridad Social -e, incluso, a los descendientes de asegurados mayores de 26 años-, cuyos ingresos superen un determinado límite que la norma no precisa. Pero lo más grave es la expulsión de la cobertura pública sanitaria de los extranjeros sin permiso de residencia, con las graves consecuencias que implica en términos de salud individual, salud colectiva o salud pública, además del recorte de derechos que supone y que no respeta principios constitucionales como es el de la dignidad de la persona. En consecuencia, debe realizarse una puntualización respecto del ámbito subjetivo. En relación al status jurídico del extranjero, la CE, en su art.13, establece que «los extranjeros gozarán en España de las libertades públicas que garantiza el presente Título en los términos que establezcan los tratados y la ley»; por lo tanto, en principio, los extranjeros quedan asimilados a los ciudadanos españoles, siempre de acuerdo con lo dispuesto en dichas normas. Sin embargo, la regulación de los derechos de los extranjeros no llegó hasta 1985, cuando entró en vigor la Ley Orgánica 7/1985, de 1 de julio sobre derechos y libertades de los extranjeros. Antes de la promulgación de dicha norma, el TC ya se había pronunciado a este respecto en la sentencia 107/1984, una resolución de suma importancia para la regulación de los derechos de los extranjeros pues determinó, por primera vez, que estos poseían determinados derechos inherentes a la dignidad de la persona, de acuerdo con lo establecido en el art. 10.1 CE; así expresaba el TC que «los derechos y libertades reconocidos a los extranjeros siguen siendo derechos constitucionales $\mathrm{y}$, por tanto, dotados -dentro de su específica regulación- de la protección constitucional, pero son todos ellos sin excepción en cuanto a su contenido derechos de configuración legal». Es decir, para el ejercicio del derecho del titular, hay así una completa igualdad entre españoles y extranjeros, como la que efectivamente se da respecto de aquellos derechos que atañen a la persona en cuanto tal y no como ciudadano, 


\section{Jesús Esteban CÁrcar Benito}

o, si se rehúye esta terminología, ciertamente equívoca, de aquellos que son imprescindibles para la garantía de la dignidad humana, esto en relación con el derecho a la vida, la integridad física ${ }^{68}$ y psíquica, la libertad ideológica o la intimidad, sin que quepa un trato diferenciado entre los extranjeros y los españoles.

Además, la dignidad de la persona es la plataforma de cualquier regulación de derechos fundamentales y «la característica propia e inseparable de toda persona en virtud de su racionalidad - independientemente del momento y por encima de las circunstancias en que se desenvuelva su vida- que se materializa en la realización, desarrollo y perfección de la propia personalidad a través del ejercicio de los derechos inviolables e irrenunciables que le son inherentes» ${ }^{69}$; y ello a pesar de que el legislador lo haya olvidado en algún momento y haya sido el TC el órgano que ha corregido las desviaciones legislativas en relación con los derechos fundamentales, teniendo en cuenta además el desarrollo del fenómeno migratorio en España.

De hecho, y en relación directa con los derechos sociales ${ }^{70}$, se encuentra el marco interpretativo reflejado en las sentencias del TC 236/2007 y 259/2007 recaídas sobre los recursos de inconstitucionalidad presentados contra la LO 4/2000 reformada por la LO 8/2000 sobre los derechos y libertades de los extranjeros ${ }^{71}$, que niega al legislador ir más allá de su contenido constitucionalmente declarado.

${ }^{68}$ Auto del Tribunal Constitucional 239/2012, de 12 de diciembre en el que se señala que «El derecho a la salud y el derecho a la integridad física poseen una importancia singular en el marco constitucional que no puede verse desvirtuado por la mera consideración de un eventual ahorro económico» o también cuando afirma que «Los intereses generales y públicos vinculados a la promoción y garantía del derecho a la salud, son intereses asociados a la defensa de intereses constitucionales particularmente sensibles». A nivel comunitario, merece citarse el Auto del Tribunal de Justicia de la UE de 12 de julio de 1996 sobre el asunto de las vacas locas.

${ }^{69}$ ALEGRE MARTÍNEZ M. A., La dignidad de la persona como fundamento del ordenamiento constitucional español, Universidad de León, 1996.

${ }^{70}$ TERRÁDEZ SALOM D., "La importancia de la interacción entre normativa y jurisprudencia en el diseño del estatus jurídico del extranjero» (85-112) Revista CEF Legal, n. ${ }^{\circ} 106$, noviembre 2009.

${ }^{71}$ Sentencia del TC 236/2007, de 7 de noviembre de 2007, BOE núm. 295 de 10 de diciembre de 2007; Sentencia del TC 259/2007, de 19 de diciembre de 2007, BOE núm. 19 de 22 de enero de 2008; Ley Orgánica 8/2000, 22 diciembre, de reforma de la LO 4/2000, de 11 de enero, sobre derechos y libertades de los extranjeros en España y su integración social; BOE núm. 307 de 23 diciembre. 18 residencia y trabajo el ejercicio del derecho de huelga, sindicación o asociación, entre otros. La temprana reforma de la LO 4/2000, apenas unos meses después de su entrada en vigor, trajo consigo una importante, y grave, disminución de los derechos fundamentales de los que podían gozar no sólo los extranjeros en situación regular, sino también los que no ostentaban una autorización para residir y trabajar, siendo estos últimos los más perjudicados, pues se condicionaron a la posesión de autorización (Fundamento ju- 
De acuerdo con lo debatido, el RDL 16/2012 dejó fuera del sistema público de salud a los extranjeros en situación irregular, argumentando la medida en la necesidad de reducir el déficit económico de la sanidad pública, provocado por el turismo sanitario. Pese a advertir que el RDL 16/2012 tiene la intención de hacer sostenible el sistema sanitario hay que afirmar que denegar el acceso de los extranjeros, en situación irregular, a la asistencia sanitaria supone una vulneración de normas internacionales (art. 11 de la CSE) ${ }^{72}$. A mayor abundamiento, la asistencia sanitaria es un prerrequisito para la preservación de la dignidad humana, y esta es el valor fundamental y además el núcleo de la normativa de Derechos Humanos, lo que evidencia no solo la importancia del derecho a la salud, sino también la necesidad de establecer el principio de indivisibilidad de los derechos humanos para que la dignidad humana quede garantizada.

En cuanto a las razones que alega el legislador español respecto de la necesidad de las medidas adoptadas en el RDL 16/2012 para evitar un crecimiento del déficit económico, la crisis económica entiendo que no puede servir como excusa para la restricción o denegación del acceso a la asistencia sanitaria, existiendo una relación con el artículo 15 que recoge el derecho fundamental a la vida y a la integridad física y moral de la persona humana. Además, esta actitud indiferente hacia los derechos sociales, llegando incluso a disponer de ellos bajo argumentos economicistas, coste-beneficio, introduce aún más la brecha entre los derechos civiles y los derechos sociales, violando así el principio de indivisibilidad de los derechos fundamentales. Ello es así, según destaca BAYÓN, porque los derechos fundamentales se caracterizan por ser «límites a la adopción de políticas basadas en cálculos coste-beneficio», lo cual representa que estos derechos pretenden amurallar ciertos bienes que, dice el autor, «deberían asegurarse incondicionalmente para cada individuo, poniéndolos a resguardo de eventuales sacrificios basados en consideraciones agresivas ${ }^{73}$.

En el plano internacional, se reclama el acceso a los servicios de salud de todas las personas que residen en su territorio, cualquiera que sea su situación administrativa, en consonancia con el principio

rídico 3, sentencia del TC 107/1984, de 23 de noviembre; BOE núm. 305 de 21 de diciembre de 1984).

72 SALCEDO BELTRÁN C., "Incumplimientos por España de la Carta Social Europea. Conclusiones XX-2 (2013) del Comité Europeo de Derechos Sociales», Estudios $n .^{\circ} 82$, Fundación $1 .^{\circ}$ de mayo, febrero 2014, p. 69.

${ }^{73}$ BAYÓN, J. C. «Derechos, democracia y constitución», Discusiones, n. ${ }^{\circ}$ 1, p. 65 


\section{Jesús Esteban CÁrcar Benito}

de universalidad de las prestaciones sanitarias ${ }^{74}$. Sin embargo, la universalidad en cuanto a los titulares del derecho tendría una excepción, o más bien una matización respecto a su alcance. Es conocido que BOBBIO destacó el proceso que denominó de especificación, como una de las líneas de evolución histórica de los derechos fundamentales ${ }^{75}$. Ahora bien, el proceso de especificación supone la consideración de determinadas situaciones especiales de vulnerabilidad social a la hora de asignar derechos, cuestión que no tiene en cuenta el RDL 16/2012.

O dicho de otra forma, habría que señalar que las condiciones de acceso a la asistencia sanitaria de los grupos de población en situación de exclusión social, como son los inmigrantes irregulares sin recursos han sido contempladas como objetivos de la ONU (formas contemporáneas de racismo, discriminación racial, xenofobia y otras formas conexas de intolerancia) y recomiendan la revisión de las medidas de reforma de la salud adoptadas en el contexto de la crisis económica para asegurar el acceso a la sanidad de los inmigrantes sin importar su estatus migratorio. Más recientemente, como hemos indicado, el Consejo de Europa ha advertido que cualquier otro planteamiento es contrario a derecho europeo y ha recordado que los Estados tienen la obligación de prestar asistencia sanitaria a los ciudadanos independientemente de su estatus de residencia, porque la salud es un requisito previo para la dignidad humana y el cumplimiento de los derechos humanos obliga a preservarla ${ }^{76}$.

${ }^{74}$ El Comité de Derechos Económicos, Sociales y Culturales examinó el quinto informe periódico de España sobre la aplicación del Pacto Internacional de Derechos Económicos, Sociales y Culturales (E/C.12/ESP/5) en sus sesiones $12 .^{\mathrm{a}}$ a $14 .^{\mathrm{a}}$, celebradas los días 7 y 8 de mayo de 2012 (E/C.12/2012/SR.12 a 14), y aprobó, en su 28. ${ }^{a}$ sesión, el 18 de mayo de 2012 (E/C.12/2012/SR.28), las observaciones finales que figuran a continuación.

${ }^{75}$ BOBBIO N., El tiempo de los derechos, trad. de R de Asis. Sistemas, Madrid, 1991.

${ }^{76}$ En la Ley de Presupuestos Generales del Estado para el año 2014, se ha modificado la cobertura sanitaria de los españoles que hubieran agotado las prestaciones del sistema de protección por desempleo, que perderían su derecho a asistencia sanitaria en nuestro país si salen de España por tiempo superior a 90 días, incluso para buscar trabajo o formación. La presente Ley repone la situación jurídica previa a la promulgación del Real Decreto-ley citado. Para ello, varía otra vez la LCCSNS y el artículo 12 de la Ley Orgánica 4/2000, de 11 de enero, sobre derechos y libertades de los extranjeros en España y su integración social, volviendo a la redacción vigente antes de la entrada en vigor del Real Decreto-ley. El artículo tercero, por su parte, es similar a la disposición adicional sexta de la Ley de Salud Pública, derogada tácitamente por el Real Decreto-ley 16/2012, aunque se ha tenido en cuenta que desde el 1 de enero de 2012, por mor de la entonces vigente disposición adicional sexta, las personas que hubieran agotado la prestación o subsidio de desempleo ya tenían derecho a la asistencia sanitaria pública. 


\section{CONCLUSIÓN PARA UNA UNIVERSALIZACIÓN DEL DERECHO SOCIAL A LA ASISTENCIA SANITARIA}

Entiendo, como señala ERNESTO GARZÓN, que la asistencia sanitaria entraría dentro del coto vedado de los intereses univesalizadores o derechos humanos, no puede ser objeto de recortes productos de negociaciones parlamentarias. Ello conforma el núcleo «no negociable de una constitución democrático-liberal que propicie el Estado social de Derecho ${ }^{77}$. En el mismo sentido, para LIBORIO HIERRO, en todo caso, el alcance del rasgo de universalidad supone que no es una característica exclusiva de los derechos económicos-sociales el que se trate de derechos que se predican del ser-humano-que-trabaja o del ser humano que carece-o dicho de otra forma, que su disfrute depende de cierta situación laboral o de cierta situación de carencia ${ }^{78}$. Habría que recuperar con la universalización de la cobertura sanitaria pública el reconocimiento de una situación de igualdad entre nacionales y extranjeros, en lo que al artículo $43 \mathrm{CE}$ respecta, que encuentra su justificación constitucional en la vinculación que este precepto ostenta con el principio constitucional de dignidad de la persona (artículo 10.1 CE), requisito ineludible para el reconocimiento del derecho a la vida y a la integridad física y moral (artículo 15). Tanto de las normas de protección de los Derechos Humanos en el ámbito internacional y comunitario -(Declaración Universal de los Derechos Humanos -art. 25-), como de la Jurisprudencia del Tribunal Europeo de Derechos Humano, así lo referencian-.

La solución radica, por lo tanto, en una concepción en la que los derechos humanos, como derechos fundamentales, sean algo más, conformen una categoría unitaria: en su carácter de facultades o títulos básicos asociados a la dignidad y autonomía moral humana, esto es, a las condiciones para su ejercicio. Se establece, en ello, una proyección del derecho a la vida sobre el derecho a la protección de la salud y las consiguientes prestaciones sanitarias por parte de los poderes públicos, lo que redunda y confirma la configuración universal de un derecho, la asistencia sanitaria, al que deben tener acceso todas las personas, independientemente de su nacionalidad o situación administrativa Por ello, la escasez, no puede ser razón suficiente para desconocer la existencia de derechos morales tales, como el derecho a la asistencia sanitaria, aunque si pueda ser una razón para definir

${ }^{77}$ GARZÓN. E. « Representación y Democracia», Doxa n. ${ }^{\circ}$ 6,1989, p. 162.

${ }^{78}$ HIERRO L., "Los derechos económicos y sociales y el principio de igualdad en la teoría de los derechos de Robert Alexy», Doxa, Cuadernos de Filosofía del Derecho,.n. ${ }^{\circ} 30,2007$, pp. 249-271. 


\section{Jesús Esteban CÁrcar Benito}

su contenido ${ }^{79}$. Si los derechos humanos son, por igual, responsabilidad de todos, nadie tiene el deber preferente de responder por ellos, deber entre el todo ${ }^{80}$.

Como señala RUIZ MIGUEL, se debe distinguir entre el reconocimiento de un derecho, es decir, su carácter universal, y los problemas asociados a su realización efectivamente universal. El incumplimiento de recursos "no sólo no impugna aquella universalidad sino que denuncia su ausencia» ${ }^{81}$. Negar la universalidad atribuiría la negación misma de los derechos humanos. En palabras de HABERMAS con relación a la universalidad de ciertos valores, la asistencia sanitaria no es una excepción: "Nuestro ordenamiento jurídico descansa sobre principios fundamentales de contenido universal y la realización de tales principio puede entenderse como el agotamiento de este contenido. Normas como los derechos fundamentales, la garantía del procedimiento judicial, el principio de soberanía popular, la separación de poderes, el principio del Estado social, etc, están formuladas inevitablemente en un alto escalón de abstracción. Estos principios tendría que tener una vigencia universal, esto es, valer en todo momento y espacio, para todo y para todos y también para otras normas que enjuiciamos según estas medidas» ${ }^{82}$.

${ }^{79}$ LORA P.; ZÚÑIGA FAJURI A., op. cit.

${ }^{80}$ CURREA-LUGO, V., La salud como derecho humano, Bilbao; Universidad de Deusto, Instituto de Derechos Humanos, 2005, p. 19.

${ }^{81}$ RUIZ MIGUEL, A., «Derechos liberales y derechos sociales» Doxa, n. ${ }^{0}$ 15-16 pp. 651-674.

${ }^{82}$ HABERMAS J., Ensayos Políticos, Ed Península, Barcelona, 1998. Traducción Ramón García Cotarelo, pp. 83-84. 